\title{
ZONAL MODEL FOR AN EFFECTIVE SIMULATION OF HEAT TRANSFER PROCESSES IN WALKING BEAM STEEL REHEATING FURNACES
}

\author{
Michal ŠVANTNER, Josef ŠTUDENT, Zdeněk VESELÝ \\ University of West Bohemia, Pilsen, Czech Republic, EU, \\ msvantne@ntc.zcu.cz, student;@ntc.zcu.cz, zvesely@ntc.zcu.cz
}

https://doi.org/10.37904/metal.2019.675

\begin{abstract}
Continuous steel reheating furnaces belong to high-energy consumption units and an optimization of their operation can thus bring significant economic and ecological benefits. Numerical modelling is one of the tools for an optimization of a design, process parameters and operation control of the furnaces. A 3D zonal model of a continuous gas burners heated walking-beam furnace is introduced in this contribution. A solution of heat transfer process in the furnace is based on a Hottel zonal method and compartment based discretization. The solution includes convective and radiative heat transfer in the furnace including a participation of a semitransparent gaseous furnace atmosphere. A method of direct measurement of a charge heating in a continuous walking beam furnace is presented. The method is based on a thermal-box barrier device, which allows temperature measurement of a tested beam during its entire passage throughout the furnace. Results obtained by the numerical simulation and the measurement are compared and a good agreement is confirmed. It is demonstrated that the presented zonal model is an effective tool, which can bring accurate enough results at a very acceptable time.
\end{abstract}

Keywords: Walking-beam furnace, steel reheating, radiation heat transfer, numerical model, zonal method, temperature measurement, thermal box-barrier

\section{INTRODUCTION}

Periodical, continuous or carrousel type furnaces [1] are often used for heat treatment of products or their heating before subsequent technological operations. The processing temperatures in industrial continuous furnaces for steel reheating often exceeds $1,000^{\circ} \mathrm{C}$ and are very large energy consumers. An optimization of their operation can therefore bring financial savings as well as technological improvements and reduction of production of environmentally harmful substances.

The optimization of the furnace s operation is mostly based on a numerical modeling. Complex numerical models based on continuum fluid dynamics are developed for a detailed description of the processes inside the furnace. These models are mostly very extensive and not suitable for an on-line optimization or processing parameters adjustment. Such a complex walking-beam continuous furnace 3D model is presented for example in [2] or [3]. Simplified numerical models are developed for an optimization of a furnace operation process. Different simplifications are used in these approaches, for example geometrical simplifications or solved thermal processes reduction. These models are fast enough for an on-line optimization of the furnace operation, however, a lot of empirical knowledge are mostly required for their reliability. Such a model developed for a continuous furnace optimal heating control system is introduced for example in [4]. Except of these approaches, numerical procedures with an acceptable variability, solution accuracy and computing speed are developed [5].

Often used approaches use zonal models, which are used for numerical modelling of furnaces for example in [6], [7] or [8]. These models are based on dividing of the furnace volume to several zones and a separate solution of heat transfer inside the zones and heat exchange between the zones. The 3D zonal model based solution was adapted in this work for a walking beam type furnace. The model introduced combines analytical procedures of radiation view factors computation with a numerical solution of the heat transfer problem. The 
solution includes radiation, convection, participating of a semi-transparent gaseous media, charge movement, heat transfer in charge and heat transfer in furnace parts. The used approach allows developing of a flexible and adaptable model, which solution is fast enough for an engineering computations including furnace and processing parameters design, for example.

\section{WALKING BEAM FURNACE}

Walking beam furnace [2][9] is a continuous type furnace, in which a charge moves through the furnace from one end to the other. The charge is distributed in the furnace with spaces between individual beams, which are moved by a walking mechanism. The charge heating process is mostly defined by a heating curve and a control systems of the furnace adjusts a temperature in the furnace zones in such a way that the charge temperature corresponds to the temperature prescribed by a heating curve.

A definition of heat transfer processes in the furnace is crucial for design of the furnace and control of the heating process. Both convection and radiation heat transfer are involved in processes inside the furnace. However, the radiation heat transfer is mostly dominant at high temperatures. Two important features are related to the radiation heat transfer in gas burners heated walking beam furnaces, which are the subject of this research. The first one is connected with specific combustion products properties, which are partially transparent and their radiation properties depends on their chemical composition, temperature and a thermodynamic state. The second one is connected with a geometrical configuration. Each piece of the charge moves individually throughout the furnace and changes its position during the heating process. Thus, geometrical definitions for the radiation heat transfer are more complicated than in furnaces with a constant geometrical configuration.

\section{NUMERICAL MODEL AND EXPERIMENT DESCRIPTION}

A gas burners heated continuous walking beam furnace for steel beams reheating was an object of our research. The furnace length and width was $43 \mathrm{~m}$ and $9 \mathrm{~m}$, respectively. The furnace had a capacity of 65 beams and the length of one step of a movement of the beams was $660 \mathrm{~mm}$. The charge-beams had a circular cross section of diameter $410 \mathrm{~mm}$ and their length was $5,500 \mathrm{~mm}$. The beam passed though the furnace about $450 \mathrm{~min}$ and its maximum temperature in the soaking zone was about $1,300^{\circ} \mathrm{C}$. The beams were moved by a water-cooled walking mechanism.

A zonal model was developed for a numerical computation of a heating process in the furnace. It includes all significant energy balance and heat transfer processes in the furnace:

- $\quad$ Heat input into the furnace due to burners including combustion process inside the furnace.

- Heat exchange inside the furnace - heat transfer (radiation, convection or conduction) between combustion products, furnace internal parts and charge.

- Internal heat transfer - heat transfer inside charge, furnace walls and other furnace internal parts.

- Input / removal of the charge into / from the furnace, respectively, and moving of charge in the furnace.

- Heat removal by combustion products outlet through a chimney, heat transfer to a furnace surroundings or heat removal by cooling water.

It is a 3D transient model, which combines discretization based numerical computations with simplifications based on empirical knowledge or experimental calibrations. Some geometrical simplifications were used, but the model in principle respects geometrical relations and their changes, i.e. a charge movement. The furnace was divided into several zones. An average temperature of combustion products is assumed in one zone. The heat transfer problem is solved according to the Hottel zonal method in each zone and each time step. Individual charge pieces (beams) and furnace walls are divided into compartments, between which there is conduction heat transfer. Material properties of the charge, furnace parts and combustion products are 
temperature dependent. Combustion products flow is not solved but a heat transfer coefficient is estimated based on conditions in individual zones. Similarly, heat loses in zones are also set based on empirical knowledge. Interaction between individual zones is limited to a transfer of the combustion products and beams. Energy balance between entering and leaving heat/mass flow is then solved for each zone. The model works as transient and a steady state is achieved by a sufficiently long computational time, which was set to 15 hours in this case. The simulation results are temperature distribution in the beams during their passage throughout the furnace and other thermal information, for example energy consumption or heat fluxes.

Results of the numerical modelling were verified by a direct measurement of an experimental beam. The measurement was performed in a similar way as described in [10]. Temperature of the beam during its passage throughout the furnace was measured by thermocouples at different positions. The thermocouples were connected to a data-logger, which was placed inside a thermal box-barrier (TBB). The TBB moved together with the experimental beam throughout the furnace and protected the data-logger against high temperatures. The data-logger was removed from the TBB after its output from the furnace and measured data were transferred and saved to a control computer.

\section{RESULTS}

The furnace temperature measured by the thermocouple near a top surface of the beam increased up to about $700{ }^{\circ} \mathrm{C}$ immediately after the beam entered the furnace. Then it increased up to about $1,300{ }^{\circ} \mathrm{C}$ in time $250-$ $350 \mathrm{~min}$. The furnace temperature then remained stable (a soaking zone) at the level about $1,300{ }^{\circ} \mathrm{C}$ up to an output of the beam from the furnace. The temperature at the beam axis increased from the initial temperature $\left(2-10^{\circ} \mathrm{C}\right.$ ) to about $700{ }^{\circ} \mathrm{C}$ in $200 \mathrm{~min}$ and to about $1,270{ }^{\circ} \mathrm{C}$ in $400 \mathrm{~min}$. The beam temperature then was homogenized and increased slightly up to the furnace atmosphere temperature $1,300{ }^{\circ} \mathrm{C}$ at the end of the furnace.

A comparison of the measured and simulated results in Figure 1 showed that the furnace atmosphere temperatures were in a good accordance. The simulated beam temperatures were higher than the measured of about $100{ }^{\circ} \mathrm{C}$ in a $1^{\text {st }}$ heating phase in time to about 150 min. However, the simulated and measured temperatures came together in next phases of the heating process and were very similar at the end of the furnace, where the differences between measured and simulated temperatures in the beam axis were from 10 to $20^{\circ} \mathrm{C}$.

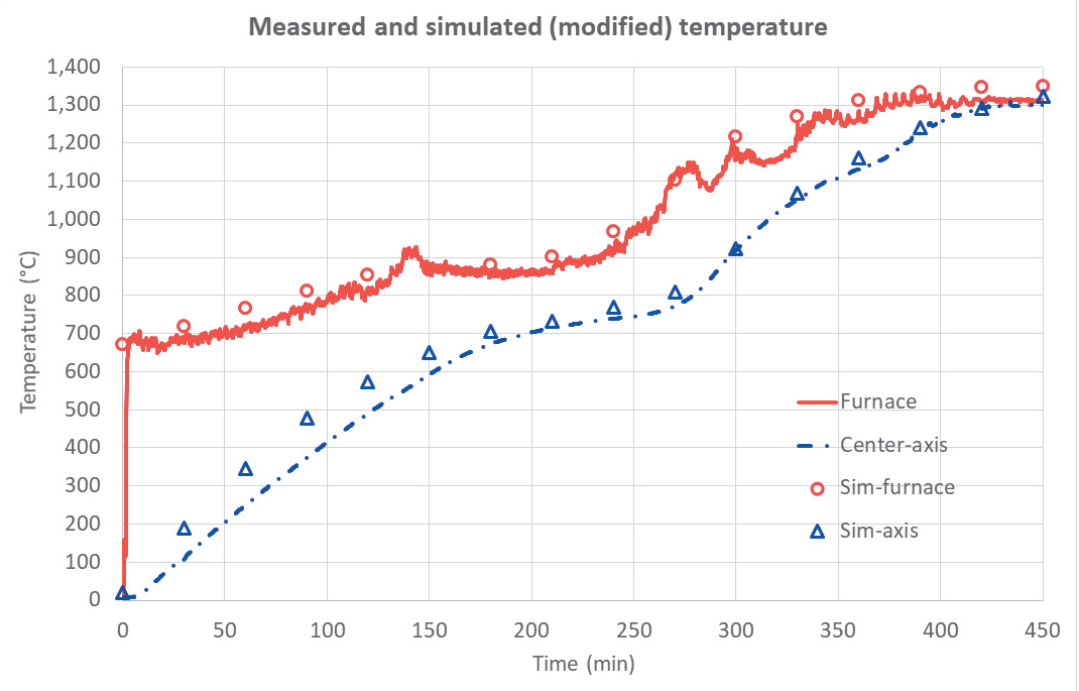

Figure 1 Measured (lines) and simulated (points) temperature of the furnace atmosphere and the experimental beam 


\section{CONCLUSION}

The numerical simulation model based on a zonal method for continuous walking beam furnace for steel beams reheating computation was introduced. Results of the numerical modelling was compared with a direct measurement, which was made by thermocouples using a thermal box-barrier. It was presented that a difference between measured and computed beam temperature was $10-20^{\circ} \mathrm{C}$ at the end of the furnace. It can thus be concluded, that a very good agreement between the measurement and numerical computation was achieved.

The used approach allowed to perform the computation of the 15 hours of the heating process using a standard personal computer in about 25 minutes. This result was significantly better than comparable full-featured finite elements or finite volumes based models. Thus, it could be an ideal tool for a furnace parameters design or for a design of a heating process parameters for different operation requirements.

\section{ACKNOWLEDGEMENTS}

The work has been supported by the Technology Agency of the Czech Republic within the project no. TE01020068 and by the Ministry of Education, Youth and Sports of the Czech Republic within the OP RDI program, CENTEM project, no. CZ.1.05/2.1.00/03.0088, co-funded by the ERDF; and National Sustainability Programme I., CENTEM PLUS project, no. LO1402.

\section{REFERENCES}

[1] TRINKS, W., MAWHINNEY, M. H., SHANNON, R. H., REED, R. J., GARVEY, J. R. Industrial Furnaces. 6th ed. New Jersey: John Wiley \& Sons, 2004. p. 496.

[2] HSIEH, C.-T., HUANG, M.-J., LEE, S.-T., WANG, C.-H. Numerical Modeling of a Walking-Beam-Type Slab Reheating Furnace. Numer. Heat Transf. Part A Appl. 2008. vol. 53, no. 9, pp. 966-981.

[3] HACHEM, E., JANNOUN, G., VEYSSET, J., HENRI, M., PIERROT, R., POITRAULT, I., MASSONI, E., COUPEZ, T. Modeling of heat transfer and turbulent flows inside industrial furnaces, Simul. Model. Pract. Theory. 2013. vol. 30, pp. 35-53.

[4] HONNER, M., VESELY, Z., ŠVANTNER, M. Exodus stochastic method application in the continuous reheating furnace control systém. Scand. J. Metall. 2004. vol. 33, no. 6, pp. 328-337.

[5] LANDFAHRER, M., SCHLUCKNER, C., PRIELER, R., GERHARDTER, H., ZMEK, T., KLARNER, J., HOCHENAUER, C. Development and application of a numerically efficient model describing a rotary hearth furnace using CFD. Energy. 2019. vol. 180, pp. 79-89.

[6] EMADI, A., SABOONCHI, A., TAHERI, M., HASSANPOUR, S. Heating characteristics of billet in a walking hearth type reheating furnace. Appl. Therm. Eng. 2014. vol. 63, no. 1, pp. 396-405.

[7] TAN, C.-K., JENKINS, J., WARD, J., BROUGHTON, J., HEELEY, A. Zone modelling of the thermal performances of a large-scale bloom reheating furnace. Appl. Therm. Eng. 2013. vol. 50, pp. 1111-1118.

[8] EBRAHIMI, H., ZAMANIYAN, A., SOLTAN MOHAMMADZADEH, J.S., KHALILI, A.A. Zonal modeling of radiative heat transfer in industrial furnaces using simplified model for exchange area calculation. Appl. Math. Model. 2013. vol. 37, pp. 8004-8015.

[9] HAN, S.H., BAEK, S.W., KIM, M.Y. Transient radiative heating characteristics of slabs in a walking beam type reheating furnace. Int. J. Heat Mass Transf. 2009. vol. 52, pp. 1005-1011.

[10] HONNER, M., ŠVANTNER, M. Thermal box-barrier for a direct measurement in high temperature environment, Appl. Therm. Eng. 2007. vol. 27, no. 2-3, pp. 560-567. 